\title{
POLÍTICAS PÚBLICAS DE EXPANSÃO DO ENSINO SUPERIOR FEDERAL NO BRASIL NO CONTEXTO DA MUNDIALIZAÇÃO DO CAPITAL
}

\author{
André Moura Blundi Filardi ${ }^{1}$ \\ Dayton Fernando Padim ${ }^{2}$
}

\section{RESUMO}

Há uma relação intrínseca entre as transformações econômicas da sociedade capitalista que ocorreram a partir dos anos 1970, a Reforma do Estado articulada no Brasil na década de 1990 e as políticas para a educação superior no país. Um breve relato - e uma análise das consequências - acerca destas relações e das transformações consequentes da educação superior no Brasil, principalmente, nas universidades federais, a partir das políticas educacionais desenvolvidas, mais recentemente, a partir da segunda metade da década dos anos 2000 é a discussão que propõe este artigo.

Palavras-chave: Políticas Públicas; Educação Superior; Universidades Federais.

\section{THE PUBLIC POLICIES OF THE FEDERAL UNIVERSITY EXPANSION IN BRAZIL IN THE CONTEXT OF THE MUNDIALIZATION OF THE CAPITAL}

\section{ABSTRACT}

There is a intrinsic relation between the economic transformations of capitalist society occurred since 70`s years, the State Reform build in Brazil in 90`s years and the public policies of superior education in the same country. A short report and analysis of consequences of these relations to superior education in Brazil and the transformations of the federal universities, from the educational policies developed, since first decade of twenty-one century is the debate representative in this article.

Keywords: Public Policies; Superior Education; Federal Universities

\section{INTRODUÇÃO}

Há reformas de maior ou menor alcance: umas pretendem apenas melhorar os aspectos de um quadro de problemas, outras ambicionam mudanças radicais. Por diferentes que sejam, têm suas motivações e ultrapassam as dimensões internas das instituições educativas e tocam na problemática do sistema educacional e da sociedade. Por isso, uma reforma educativa acaba mexendo com interesses e valores não só da comunidade educativa, mas da população mais ampla. (DIAS SOBRINHO, 2006, p.168)

Este artigo procura estabelecer relações entre o contexto das transformações da estrutura econômica mundial que se desenvolveram nos últimos trinta anos, ou seja, o processo de mundialização do capital, com as políticas públicas para o ensino superior que se desenvolveram no Brasil a partir destas transformações. Neste sentido, procura analisar como que, com este novo contexto da economia mundial, o Estado e os governos 
brasileiros lidaram com as necessidades de expansão e melhoria do ensino superior público ao mesmo tempo em que as pressões para a maior entrada de capital externo neste setor eram evidentes.

Assim, a partir da análise de dados que comparam a expansão do ensino superior em suas esferas particular e pública, trechos de documentos e tabelas organizadas pelo governo e pelo Ministério da Educação (MEC), além de textos de outros pesquisadores, também críticos ao modelo de expansão do ensino superior, conseguimos demonstrar, mesmo que parcialmente e de sucintamente, que houve uma interdependência destes processos.

O objetivo deste artigo é contribuir com a crítica ao modelo de expansão e com a desconstrução da ideologia de que, de alguma maneira, este processo poderia se apresentar de maneira democrática e servir mais aos propósitos do desenvolvimento da educação e menos aos propósitos das corporações e dos capitais privados. Afirmamos, em sentido contrário, que por conta das escolhas e das diretrizes que vem se desenvolvendo na educação superior no Brasil estamos cada vez mais interligados e participes com as esferas de modelo de economia e políticas públicas que seguem os interesses dos grandes capitais e das instituições financeiras e produtivas internacionais.

Estas prerrogativas se materializam quando analisamos os números e as condições de implantação destes programas de educação no superior no Brasil. É, portanto, uma tentativa de mostrar, na esfera material, como estes programas se concretizam na prática universitária e nas condições de educação e trabalho nestas instituições.

\section{CONTEXTO ECONÔMICO E EDUCAÇÃO}

O processo iniciado por volta da década de 1970 nomeado por François Chesnais de Mundialização do Capital é construído a partir de uma maior participação de empresas transnacionais com investimentos diretos em países emergentes. Também se configura como uma flexibilização sobre as instituições e regulamentações do Estado de bem-estar social e pela maior participação da esfera privada nas instituições públicas. Há um novo modelo de desenvolvimento, a acumulação flexível, que consiste em buscar a flexibilização das relações trabalhistas e o aumento das taxas de lucro a partir de novas configurações do sistema de produção, conforme Harvey (1992):

A acumulação flexível (...) é marcada por um confronto direto com a rigidez do fordismo. Ela se apoia na flexibilidade dos processos de trabalho, novos mercados de trabalho, dos produtos e padrões. Caracteriza-se pelo surgimento de setores de produção inteiramente novos, novas maneiras de fornecimento de serviços financeiros, novos mercados e, sobretudo, taxas altamente intensificadas de inovação comercial, tecnológica e organizacional. A acumulação flexível envolve rápidas mudanças dos padrões de desenvolvimento desigual, tanto entre setores como entre regiões geográficas, criando, por exemplo, um vasto movimento no emprego do chamado "setor de serviços", bem como conjuntos industriais completamente novos em regiões até então subdesenvolvidas (tais como, a Terceira Itália, Flandres, vários vales e gargantas de silício, para não falar da vasta profusão de atividades dos países recém-industrializados). (HARVEY, 1992, p. 140)

Este processo traz implicações e contradições que levam a reformulação do modelo de financiamento das políticas públicas. No Brasil este se apresenta de maneira mais 
categórica a partir da Reforma do Estado do início dos anos 1990 concomitantemente à implantação do modelo gerencial de gestão pública, conforme enfatiza Bresser-Pereira:

O objetivo da Reforma da Gestão Pública de 1995 é contribuir para a formação no Brasil de um aparelho de Estado forte e eficiente. Ela compreende três dimensões: a) uma dimensão institucional-legal, voltada à descentralização da estrutura organizacional do aparelho do Estado através da criação de novos formatos organizacionais, como as agências executivas, regulatórias, e as organizações sociais; b) uma dimensão de gestão, definida pela maior autonomia e a introdução de três novas formas de responsabilização dos gestores - a administração por resultados, a competição administrada por excelência, e o controle social - em substituição parcial dos regulamentos rígidos, da supervisão e da auditoria, que caracterizam a administração burocrática; e c) uma dimensão cultural, de mudança de mentalidade, visando passar da desconfiança generalizada que caracteriza a administração burocrática para uma confiança maior, ainda que limitada, própria da administração gerencial. (PEREIRA em <http://www.bresserpereira.org.br/rgp.asp> Acesso em 12/09/2011). Grifo nosso.

Portanto, a reforma da gestão pública tem como desafio trazer para a sociedade civil organizada tarefas de participação e controle até então não utilizadas. As funções do estado passam a ser terceirizadas e as agências reguladoras passam a ser instrumento de controle dos serviços públicos e privados. A avaliação externa e a competitividade são implantadas e os órgãos públicos devem responder com maior eficiência às suas demandas.

Estas diretrizes começam a reger os serviços públicos estabelecendo a lógica da racionalidade instrumental dentro do próprio funcionalismo público. O pragmatismo que se apresenta auxilia na composição da ideologia de um funcionalismo empresarial. Ou seja, a competitividade é incentivada como um mecanismo para o aumento da produtividade. Para a estrutura e dinâmica das universidades estes novos parâmetros de administração incorporam uma heteronomia, no sentido de que são parâmetros externos, vindos do Ministério da Educação. É uma contradição que se faz presente no discurso de implantação do REUNI (Programa de Apoio a Planos de Reestruturação da Educação Superior de 2007): o governo escreve e proclama autonomia universitária, mas incentiva às Universidades a aderirem ao Programa a partir de critérios externos a ela e a partir de um modelo de avaliação externa e sob critérios da lógica produtivista.

Este modelo busca soluções para a expansão das Universidades Públicas, que se faz necessária a partir do novo modelo de acumulação flexível, que enfatizam uma intensificação do trabalho em todos os níveis da Universidade. O trabalho docente passa a ser medido a partir de sua produtividade. Esta lógica incentiva, desta maneira, que a produção acadêmica e científica acompanhe a velocidade da produção e reprodução do capital. E, se possível, participe desta dinâmica de maneira ativa.

Este processo carrega consigo uma série de implicações para a dinâmica da Universidade e para o trabalho docente. A Universidade se encontra mais ligada àquela lógica reprodutivista e o trabalho docente perde parte de seu sentido e autonomia.

Com o início do século XXI, há a consolidação deste modelo supracitado. No entanto, não se trata de mera continuidade, sobretudo quando se considera a política de expansão do ensino superior. Nesta há diversas contradições, como o modelo de implantação do REUNI, mas há uma mudança de direção em relação à política pública para a educação superior adotada nos governos anteriores. 
Em um quadro sintético da expansão do número das funções docentes nas universidades entre 1995/2003 e 2003/2010 se visualiza esta mudança:

Tabela 1: Evolução do número de funções docentes em exercício no Brasil, na rede federal, 1995/20022003/2010.

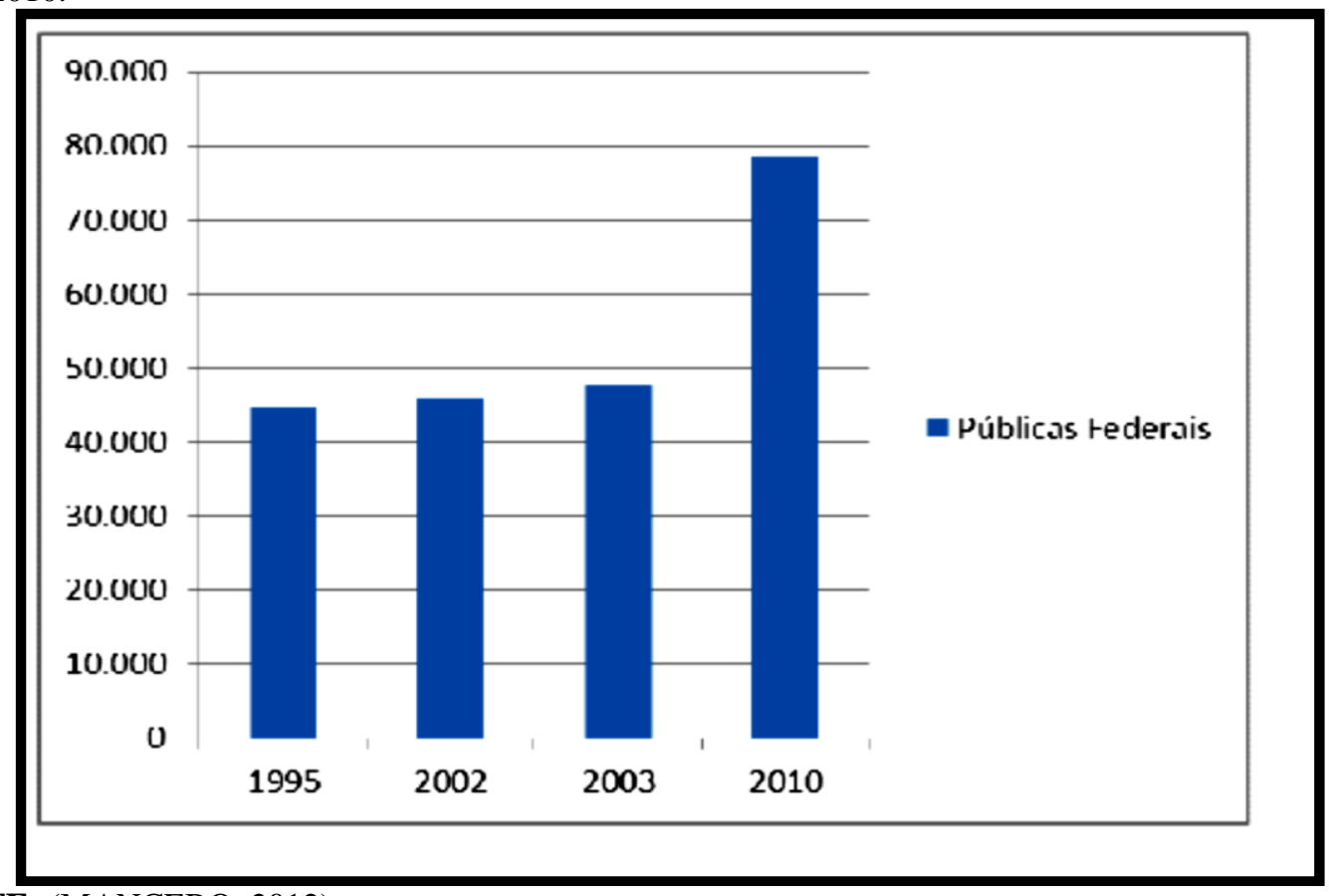

FONTE: (MANCEBO, 2012).

É notável que, a partir do ano de 2003, a política para a docência nas Universidades Federais apresenta uma mudança de direção. Há uma expansão substancial nas vagas docentes. Mas, esta política aponta contradições que serão apontadas na análise do REUNI e no modelo de expansão da rede federal de ensino superior.

A expansão da rede de ensino superior no Brasil se estrutura a partir da Reforma do Estado e, principalmente, a partir da promulgação do Reuni - Programa de Apoio a Planos de Reestruturação e Expansão das Universidades Federais - instituído pelo Decreto $\mathrm{n}^{\circ}$ 6.096, de 24 de abril de 2007, pelo Governo Lula. Com este Programa, o Governo Federal busca uma intensificação do ritmo de trabalho e produção e reprodução acadêmica e científica nas Universidades. Tanto com a expansão e intensificação do trabalho docente como pela expansão do número de discentes. Este último faz-se em parte da decorrência do primeiro.

A reformulação da educação superior, que está sendo realizada pelo governo Lula da Silva, encontra- se inserida em um processo mais amplo de reordenamento do Estado brasileiro, caracterizado pela sistemática diluição das fronteiras entre público e privado, a partir da materialização da noção de público não estatal operada pelas parcerias entre o público e o privado. Esse processo atravessou o governo Cardoso, quando a educação foi incluída no setor de atividades não exclusivas do Estado (SILVA JR. e \& SGUISSARD, 1999), e está sendo aprofundado no atual governo por meio de mais uma fase da reforma da educação superior (NEVES, 2004; NEVES e \& SIQUEIRA, 2006 e LIMA, 2007). (LIMA, 2009, p. 20). 
Entretanto, podemos perceber alguma mudança nesse sentido a partir do primeiro mandato do Presidente Luiz Inácio Lula da Silva, quando o Grupo Executivo instituído pelo Governo Federal, em fevereiro de 2004, coordenado por Fernando Haddad, elaborou o documento Reafirmando princípios e consolidando diretrizes da reforma da educação superior (BRASIL, 2004a), que entre outras ações, sugeria a criação de novas Universidades e outros Campi fora de sede vinculados às Instituições Federais existentes. A ideia veiculada pelo grupo pode ser resumida na frase de efeito: "Expandir até ficar do tamanho do Brasil".

Vale salientar que um processo de expansão e interiorização que fosse efetivamente relacionado a uma democratização, pressuporia responsabilidade social que teria que "ser assumida pela universidade, aceitando ser permeável às demandas sociais, sobretudo àquelas oriundas de grupos sociais que não têm poder para as impor." (SANTOS, 2004, pág. 89).

Não podemos, no entanto, deixar de lembrar outro papel da universidade, como Teixeira reforça na seguinte passagem:

A função da universidade é uma função única e exclusiva. Não se trata somente de difundir conhecimentos. O livro também os difunde. Não se trata, somente, de conservar a experiência humana. O livro também a conserva. Não se trata, somente, de preparar práticos ou profissionais, de ofícios ou artes. A aprendizagem direta os prepara, ou, em último caso, escolas muito mais singelas do que as universidades.

Trata-se de manter uma atmosfera de saber para se preparar o homem que o serve e o desenvolve. Trata-se de conservar o saber vivo e não morto, nos livros ou no empirismo das práticas não intelectualizadas. Trata-se de formular intelectualmente a experiência humana, sempre renovada, para que a mesma se torne consciente e progressiva. (TEIXEIRA, 1998, p. 35)

\section{EXPANSÃO DO ENSINO SUPERIOR}

A Lei 9394 de 1996 descreve:

Art. 16. O sistema federal de ensino compreende:

I - as instituições de ensino mantidas pela União;

II - as instituições de educação superior criadas e mantidas pela iniciativa privada;

III - os órgãos federais de educação.

(...)

Art. 55. Caberá à União assegurar, anualmente, em seu Orçamento Geral, recursos suficientes para manutenção e desenvolvimento das instituições de educação superior por ela mantidas. (BRASIL, 1996a)

Após a aprovação da LDB, o governo federal, tem como principal responsabilidade, fiscalizar e prover o ensino superior em nível nacional, tanto público quanto privado, sendo o último apenas fiscalizado.

Durante o Governo de FHC, e principalmente após a aprovação da LDB, ocorreu uma diminuição da presença do Estado na educação superior, principalmente por conta da expansão da rede privada nesta modalidade de ensino e pela abertura ao capital externo.

Como fonte de dados os resumos técnicos dos censos da educação superior disponíveis no site do Instituto Nacional de Estudos e Pesquisas Educacionais Anísio Teixeira (INEP), responsável por confeccionar o censo e o tornar público, ilustra o 
processo.

Tabela 2: Distribuição Percentual do Número de Instituições de Educação Superior, por Categoria Administrativa - Brasil 1991-2002.

\begin{tabular}{|r|r|r|r|r|r|}
\hline \multicolumn{1}{|c|}{ Ano } & \multicolumn{1}{c|}{ Total } & \multicolumn{1}{c|}{ Pública } & \multicolumn{1}{c|}{$\%$} & \multicolumn{1}{c|}{ Privada } & \multicolumn{1}{c|}{$\%$} \\
\hline 1991 & $\mathbf{8 9 3}$ & 222 & 24,9 & 671 & 75,1 \\
\hline 1992 & $\mathbf{8 9 3}$ & 227 & 25,4 & 666 & 74,6 \\
\hline 1993 & $\mathbf{8 7 3}$ & 221 & 25,3 & 652 & 74,7 \\
\hline 1994 & $\mathbf{8 5 1}$ & 218 & 25,6 & 633 & 74,4 \\
\hline 1995 & $\mathbf{8 9 4}$ & 210 & 23,5 & 684 & 76,5 \\
\hline 1996 & $\mathbf{9 2 2}$ & 211 & 22,9 & 711 & 77,1 \\
\hline 1997 & $\mathbf{9 0 0}$ & 211 & 23,4 & 689 & 76,6 \\
\hline 1998 & $\mathbf{9 7 3}$ & 209 & 21,5 & 764 & 78,5 \\
\hline 1999 & $\mathbf{1 . 0 9 7}$ & 192 & 17,5 & 905 & 82,5 \\
\hline 2000 & $\mathbf{1 . 1 8 0}$ & 176 & 14,9 & 1.004 & 85,1 \\
\hline 2001 & $\mathbf{1 . 3 9 1}$ & 183 & 13,2 & 1.208 & 86,8 \\
\hline 2002 & $\mathbf{1 . 6 3 7}$ & 195 & 11,9 & 1.442 & 88,1 \\
\hline \hline
\end{tabular}

FONTE: (BRASIL, 2002a).

Do período de 1991 a 1996, ano da aprovação da LDB, a quantidade de instituições públicas, diminuiu cerca de 5\%. No mesmo período, houve um aumento de $6 \%$ nas instituições privadas, o que demonstra, mesmo que sutilmente, os impactos das políticas de reforma do Estado. Vale salientar que os números começam a mostrar variações principalmente no governo FHC.

Após a aprovação da LDB, observando apenas o período de 1997 a 2002, continuou o decréscimo de instituições públicas, tendo variação de quase $8 \%$ e as instituições privadas cresceram 109\% no mesmo período.

Se observadas as variações em números totais de instituições, as públicas perderam mais da metade do espaço educacional de ensino superior, as instituições privadas ocuparam este espaço, principalmente, pela não ação das políticas educacionais daquele governo ou pelo privilégio dado às instituições particulares.

Após a saída de FHC do governo, o presidente LULA deu início a políticas educacionais de expansão da rede federal de ensino superior sinalizando com ideias distintas de seu antecessor em relação a esta área. 
Tabela 3: Evolução do Número de Instituições de Educação Superior por Categoria Administrativa - Brasil 2001-2010

\begin{tabular}{|c|c|c|c|c|c|c|c|c|c|c|c|}
\hline \multirow{2}{*}{ Ano } & \multirow{2}{*}{ Total } & \multicolumn{8}{|c|}{ Pública } & \multirow{2}{*}{ Privada } & \multirow{2}{*}{$\%$} \\
\hline & & Total & $\%$ & Federal & $\%$ & Estadual & $\%$ & Municipal & $\%$ & & \\
\hline 2001 & 1.391 & 183 & 13,2 & 67 & 4,8 & 63 & 4,5 & 53 & 3,8 & 1.208 & 86,8 \\
\hline 2002 & 1.637 & 195 & 11,9 & 73 & 4,5 & 65 & 4,0 & 57 & 3,5 & 1.442 & 88,1 \\
\hline 2003 & 1.859 & 207 & 11,1 & 83 & 4,5 & 65 & 3,5 & 59 & 3,2 & 1.652 & 88,9 \\
\hline 2004 & 2.013 & 224 & 11,1 & 87 & 4,3 & 75 & 3,7 & 62 & 3,1 & 1.789 & 88,9 \\
\hline 2005 & 2.165 & 231 & 10,7 & 97 & 4,5 & 75 & 3,5 & 59 & 2,7 & 1.934 & 89,3 \\
\hline 2006 & 2.270 & 248 & 10,9 & 105 & 4,6 & 83 & 3,7 & 60 & 2,6 & 2.022 & 89,1 \\
\hline 2007 & 2.281 & 249 & 10,9 & 106 & 4,6 & 82 & 3,6 & 61 & 2,7 & 2.032 & 89,1 \\
\hline 2008 & 2.252 & 236 & 10,5 & 93 & 4,1 & 82 & 3,6 & 61 & 2,7 & 2.016 & 89,5 \\
\hline 2009 & 2.314 & 245 & 10,6 & 94 & 4,1 & 84 & 3,6 & 67 & 2,9 & 2.069 & 89,4 \\
\hline 2010 & 2.378 & 278 & 11,7 & 99 & 4,2 & 108 & 4,5 & 71 & 3,0 & 2.100 & 88,3 \\
\hline
\end{tabular}

FONTE: (BRASIL, 2010a)

Realizando semelhante análise em relação ao governo FHC, no período de 2003 a 2010 , houve um crescimento de $35 \%$ das instituições públicas, contra um crescimento de $27 \%$ das instituições privadas, e a variação em números totais foi positiva para instituições públicas com aumento pequeno de $0,6 \%$. Para recuperar o espaço perdido para as instituições privadas o governo precisaria investir mais que os $4 \%$ do PIB, uma medida para melhorar essa desigualdade seria a aprovação da reivindicação de setores da sociedade para ampliar o investimento em educação em até $10 \%$ do PIB.

Outro dado relevante para discussão é a quantidade de matrículas no período de 1995 a 2002 e 2003 a 2010, como podemos verificar nas Tabelas 4 e 5 :

Tabela 4: Matrículas Governo FHC (1995 a 2002)

\begin{tabular}{|c|c|c|c|c|c|c|c|c|c|c|c|}
\hline \multirow{3}{*}{\multicolumn{3}{|c|}{$\begin{array}{c}\text { Unidade da Federação / } \\
\text { Categoria } \\
\text { Administrativa' }\end{array}$}} & \multicolumn{8}{|c|}{ Matrículas em Cursos de Graduação Presenciais } & \multirow[b]{2}{*}{ Variação \% } \\
\hline & & & \multirow{2}{*}{$\begin{array}{c}1995 \\
\text { TOTAL } \\
\end{array}$} & \multirow{2}{*}{$\begin{array}{c}1996 \\
\text { TOTAL } \\
\end{array}$} & \multirow{2}{*}{$\begin{array}{c}1997 \\
\text { TOTAL } \\
\end{array}$} & \multirow{2}{*}{$\begin{array}{c}1998 \\
\text { TOTAL }\end{array}$} & \multirow{2}{*}{$\begin{array}{c}1999 \\
\text { TOTAL }\end{array}$} & \multirow{3}{*}{$\begin{array}{c}2000 \\
\text { TOTAL } \\
2.694 .245\end{array}$} & \multirow{3}{*}{$\begin{array}{c}2001 \\
\text { TOTAL } \\
3030754\end{array}$} & \multirow{2}{*}{$\begin{array}{c}2002 \\
\text { TOTAL } \\
\end{array}$} & \\
\hline & & & & & & & & & & & \\
\hline Brasil & & & 1.759 .703 & 1.868 .529 & 1.945 .615 & 2.125 .958 & 2.369 .945 & & & 3.479 .913 & 97,755701 \\
\hline & Pública & & 700.540 & 735.427 & 759.182 & 804.729 & 832.022 & 887.026 & 939.225 & 1.051 .655 & 50,120621 \\
\hline & & Federal & 367.531 & 388.987 & 395.833 & 408.640 & 442.562 & 482.750 & 502.960 & 531.634 & 44,650111 \\
\hline & Privada & & 1.059 .163 & 1.133 .102 & 1.186 .433 & 1.321 .229 & 1.537 .923 & 1.807 .219 & 2.091 .529 & 2.428 .258 & 129,26197 \\
\hline
\end{tabular}

FONTE: Elaboração própria segundo dados (BRASIL, 1995-2002). Grifo nosso

Tabela 5: Matrículas Governo Lula (2003 a 2010)

\begin{tabular}{|c|c|c|c|c|c|c|c|c|c|c|c|}
\hline \multirow{3}{*}{\multicolumn{3}{|c|}{$\begin{array}{c}\text { Unidade da Federação / } \\
\text { Categoria } \\
\text { Administrativa }{ }^{1}\end{array}$}} & \multicolumn{8}{|c|}{ Matrículas em Cursos de Graduação Presenciais } & \multirow[b]{2}{*}{ Variação \% } \\
\hline & & & \multirow{2}{*}{$\frac{2003}{\text { TOTAL }}$} & \multirow{2}{*}{$\frac{2004}{\text { TOTAL }}$} & \multirow{2}{*}{$\frac{2005}{\text { TOTAL }}$} & \multirow{2}{*}{$\frac{2006}{\text { TOTAL }}$} & \multirow{2}{*}{$\frac{2007}{\text { TOTAL }}$} & \multirow{2}{*}{$\frac{2008}{\text { TOTAL }}$} & \multirow{2}{*}{$\frac{2009}{\text { TOTAL }}$} & 2010 & \\
\hline & & & & & & & & & & TOTAL & \\
\hline Brasil & & & 3.887 .022 & 4.163 .733 & 4.453.156 & 4.676 .646 & 4.880 .381 & 5.080 .056 & 5.115 .896 & 5.449 .120 & 40,187527 \\
\hline & Pública & & 1.136 .370 & 1.178 .328 & 1.192.189 & 1.209 .304 & 1.240 .968 & 1.273 .965 & 1.351.168 & 1.461 .696 & 28,628528 \\
\hline & & Federal & 567.101 & 574.584 & 579.587 & 589.821 & 615.542 & 643.101 & 752.847 & 833.934 & 47,052112 \\
\hline & Privada & & 2.750 .652 & 2.985 .405 & 3.260 .967 & 3.467.342 & 3.639 .413 & 3.806 .091 & 3.764 .728 & 3.987 .424 & 44,962867 \\
\hline
\end{tabular}

FONTE: Elaboração própria segundo dados (BRASIL, 2002-2010). Grifo nosso. 
Um dos fatores que contribuíram para que ocorresse a expansão exposta, foi o aumento no orçamento do Ministério da Educação (MEC), que mudou muito de 1995 até 2010 .

Várias discussões sobre políticas públicas voltadas para expansão da educação superior pública ocorreram no governo Lula e no início de 2004 surgiu uma proposta audaciosa, chamada de Plano de Expansão Fase I, com um orçamento de R \$ 1,6 bilhão, sendo distribuído no período de 2004 a 2008. O plano consistia em criar 14 novas universidades e 64 novos campi, visando não apenas a expansão da rede federal, mas também sua interiorização.

Gráfico 1: Orçamento Ministério da Educação

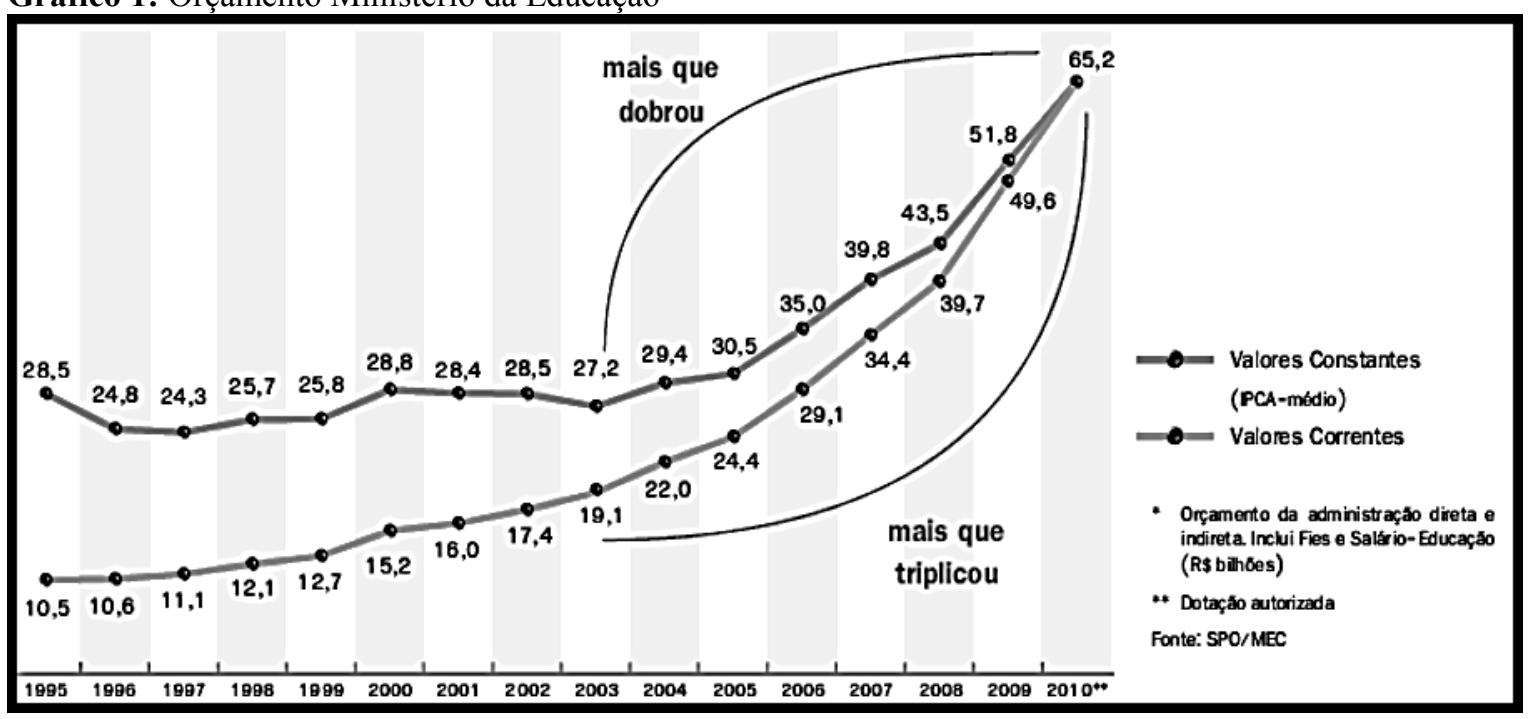

FONTE: (BRASIL, 2010a).

Em 24 de abril de 2007, foi lançado outro plano, o Programa de Apoio a Planos de Reestruturação e Expansão das Universidades Federais (REUNI), através do DECRETO $\mathrm{N}^{\mathrm{o}} 6.096$ :

Art. $1^{\circ}$ Fica instituído o Programa de Apoio a Planos de Reestruturação e Expansão das Universidades Federais - REUNI - com o objetivo de criar condições para a ampliação do acesso e permanência na educação superior, no nível de graduação, pelo melhor aproveitamento da estrutura física e de recursos humanos existentes nas universidades federais (...).

Art. $2^{\circ} \mathrm{O}$ Programa terá as seguintes diretrizes:

I - redução das taxas de evasão, ocupação de vagas ociosas e aumento de vagas de ingresso, especialmente no período noturno;

II - ampliação da mobilidade estudantil, com a implantação de regimes curriculares e sistemas de títulos que possibilitem a construção de itinerários formativos, mediante o aproveitamento de créditos e a circulação de estudantes entre instituições, cursos e programas de educação superior;

III - revisão da estrutura acadêmica, com reorganização dos cursos de graduação e atualização de metodologias de ensino-aprendizagem, buscando a constante elevação da qualidade;

IV - diversificação das modalidades de graduação, preferencialmente não voltadas à profissionalização precoce e especializada;

V - ampliação de políticas de inclusão e assistência estudantil; e

VI - articulação da graduação com a pós-graduação e da educação superior com a educação básica. (BRASIL, 2007a) 
No lançamento do plano foi designado um orçamento de $\mathrm{R} \$ 415$ milhões e até o final de 2012 seriam investidos R \$ 3,5 Bilhões, visando à implantação da reestruturação das universidades federais como previa o decreto de criação do plano. Parte deste montante não foi repassado às universidades federais até o final de 2012.

Gráfico 2: Evolução no número de funções docentes em exercício no Brasil, por organização acadêmica, $1995-2010$

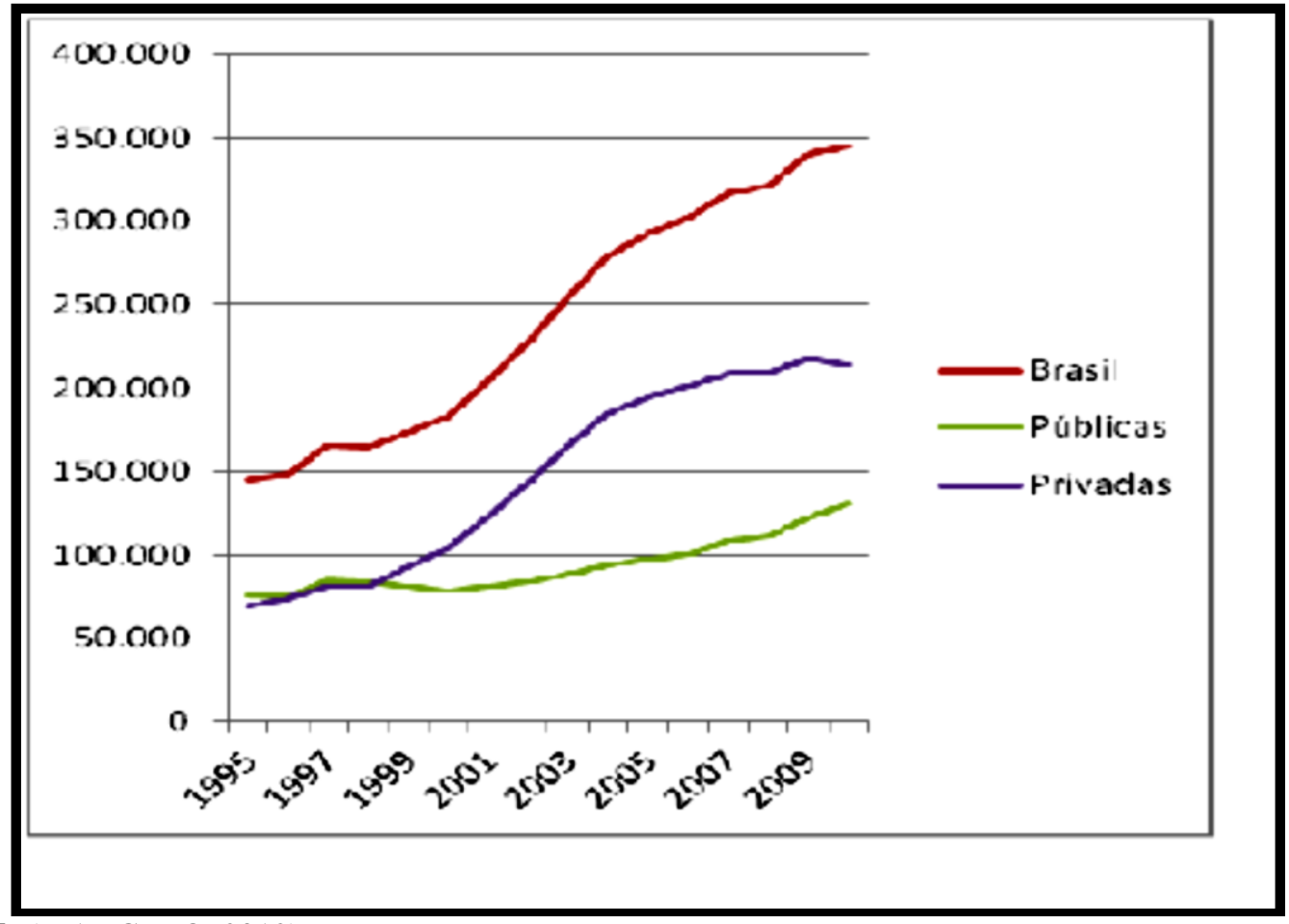

FONTE: (MANCEBO, 2012).

Observa-se que a evolução do número de professores das universidades federais é insuficiente para a expansão sugerida pelo próprio REUNI e que há um descompasso entre o plano de expansão do ensino superior público e os investimentos destinados a esta expansão. Assim, o governo se encontra em uma encruzilhada: busca apoio nas instituições federais para realizar a expansão da rede federal de ensino superior ao mesmo tempo em que destina verbas insuficientes para este projeto e intensifica as exigências sobre o corpo docente e os funcionários técnico-administrativos das mesmas.

O Plano de Expansão Fase I tinha como característica principal a expansão interiorizada e a sua proposta de criação de novas universidades e de campi vinculados a matrizes mantenedoras e administradoras.

No caso do REUNI, existe outra característica que é a expansão da matriz e também a criação de novos campi ligados a ela, mas nestes casos, são criados campi mantidos e administrados pela matriz, no entanto não tem unidade fora da sede, ou seja, os cursos são vinculados a institutos da matriz, os professores são dos institutos e têm lotação no campus que dão aula, não existem técnicos administrativos de setor meio e geralmente quando alunos e professores precisam resolver questões administrativas ou se deslocam até a matriz ou são feitos agendamentos em algum dia da semana para resolver estas questões.

Outra crítica importante é o fato de que a partir de um conjunto de leis e decretos o governo vem descaracterizando a universidade pública como uma instituição estatal, de responsabilidade do governo e do Estado. 
A adesão das universidades federais ao REUNI implica diretamente dois níveis de precarização: a da formação profissional e do trabalho docente. A precarização da formação ocorre através do atendimento de um maior número de alunos por turma, da criação de cursos de curta duração e/ou ciclos (básico e profissionalizante), representando uma formação aligeirada e desvinculada da pesquisa. Considerando a necessidade do cumprimento das metas de "expansão" apresentadas no decreto, através do aumento do número de turmas, de cursos e da relação professor-aluno em sala de aula da graduação, a dinâmica de contratação de professores nas universidades deverá pautar-se no "banco de professoresequivalentes", precarizando ainda mais as condições de trabalho docente (LIMA, 2009, p. 23)

A expansão da rede federal de educação superior ocorre de forma acelerada, em 12 anos o Brasil terá mais que duplicado o número de instituições, mas há de se ter atenção quanto à qualidade da educação, visto que, apenas a expansão não é garantia de qualidade da educação, como se pode verificar com relação à discrepância dos planos de expansão apresentados pelo governo e suas metas.

\section{CONTRADIÇÕES DA EXPANSÃO EM RELAÇÃO AO TRABALHO NAS UNIVERSIDADES}

Em tempos de expansão, o tempo útil disponível do professor-pesquisador, tende a diminuir, pois além de ministrar aulas, fazer pesquisa e extensão, agora também tem que fazer cada vez mais trabalhos administrativos, que antes eram feitos pelos técnicos.

As Tabela 6 e 7 mostram que vem diminuindo gradativamente a relação professor/técnico:

Tabela 6: Número Total de Funções Docentes (Em Exercício e Afastados), por Grau de Formação e Regime de Trabalho, segundo as Regiões Geográficas e as Instituições Federais - 1995/2010.

\begin{tabular}{|c|c|c|c|c|c|c|c|c|c|c|c|}
\hline \multirow{3}{*}{ Ano } & \multirow{3}{*}{$\begin{array}{c}\text { Região / } \\
\text { Instituições } \\
\text { Federais }\end{array}$} & \multicolumn{10}{|c|}{ Funções Docentes } \\
\hline & & \multirow[b]{2}{*}{ Total } & \multirow[b]{2}{*}{$\begin{array}{c}\text { Em } \\
\text { Exercicio }\end{array}$} & \multicolumn{5}{|c|}{ Grau de Formação (Exercicio e Afastados) } & \multicolumn{3}{|c|}{ Regime de Trabalho } \\
\hline & & & & $\begin{array}{c}\text { Sem } \\
\text { Graduação }\end{array}$ & Graduação & $\begin{array}{c}\text { Especializaçã } \\
0\end{array}$ & Mestrado & Doutorado & $\begin{array}{l}\text { Tempo } \\
\text { Integral }\end{array}$ & $\begin{array}{l}\text { Tempo } \\
\text { Parcial }\end{array}$ & Horista \\
\hline 1995 & Brasil & 51.252 & 44.486 & 67 & 8.875 & 10.220 & 15.272 & 10.052 & 35.819 & 8.667 & - \\
\hline 1997 & Brasil & 52.217 & 50.059 & 279 & 10.351 & 10.278 & 17.244 & 11.907 & 43.221 & 6.838 & - \\
\hline 1998 & Brasil & 48.622 & 45.611 & 22 & 7.745 & 8.303 & 16.371 & 13.170 & 38.709 & 6.481 & 421 \\
\hline 1999 & Brasil & - & 46.687 & 21 & 7.654 & 7.865 & 16.496 & 14.651 & 38.594 & 7.292 & 801 \\
\hline 2000 & Brasil & 50.165 & 43.739 & 17 & 7.879 & 8.201 & 17.321 & 16.747 & 42.599 & $7566^{*}$ & - \\
\hline 2004 & Brasil & 54.439 & 50.337 & 17 & 9.252 & 6.482 & 15.825 & 22.863 & 44.837 & 8.618 & 984 \\
\hline 2005 & Brasil & 56.565 & 52.943 & 13 & 9.528 & 6.601 & 15.913 & 24.510 & 47.649 & 8.697 & 219 \\
\hline 2006 & Brasil & 58.078 & 54.560 & 4 & 8.229 & 6.387 & 16.336 & 27.122 & 48.580 & 7.482 & 2.016 \\
\hline 2007 & Brasil & 63.302 & 59.156 & 14 & 9.198 & 6.195 & 17.440 & 30.455 & 53.413 & 8.500 & 1.389 \\
\hline 2008 & Brasil & 66.122 & 61.783 & 56 & 9.012 & 6.662 & 18.000 & 32.392 & 56.758 & 8.561 & 803 \\
\hline 2009 & Brasil & 77.574 & 72.228 & 53 & 11.748 & 6.145 & 20.344 & 39.284 & 63.215 & 7.985 & 1.028 \\
\hline 2010 & Brasil & 83.443 & 78.608 & 255 & 7.590 & 6.237 & 24.069 & 45.292 & 70.481 & 7.416 & 711 \\
\hline
\end{tabular}

*Inclui horista

Fonte: Elaboração própria segundo dados (BRASIL, 1995-2010). Grifo nosso. 
Tabela 7: Número Total de Funcionários Técnico-Administrativos, por Grau de Formação, segundo as Regiões Geográficas e as Instituições Federais - 1995/2010.

\begin{tabular}{|c|c|c|c|c|c|c|c|c|c|}
\hline \multirow{3}{*}{ Ano } & \multirow{3}{*}{$\begin{array}{c}\text { Região / } \\
\text { Instituições } \\
\text { Federais }\end{array}$} & \multicolumn{8}{|c|}{ Funcionários } \\
\hline & & \multirow[b]{2}{*}{ Total } & \multicolumn{7}{|c|}{ Grau de Formação (Exercício e Afastados) } \\
\hline & & & $\begin{array}{l}\text { Fundamental } \\
\text { Incompleto }\end{array}$ & $\begin{array}{c}\text { Fundamental } \\
\text { Completo }\end{array}$ & Médio & Graduação & Especialização & Mestrado & Doutorado \\
\hline 1995 & Federal & 100.517 & 19.942 & 14.579 & 35.279 & 26.187 & 3.375 & 1.025 & 130 \\
\hline 1996 & Federal & 98.058 & 18.981 & 13.547 & 35.874 & 24.829 & 3.447 & 1.121 & 259 \\
\hline 1997 & Federal & 91.042 & 17.414 & 11.861 & 35.083 & 23.066 & 2.691 & 765 & 162 \\
\hline 1998 & Federal & 75.122 & 14.977 & 10.064 & 28.278 & 18.687 & 2.235 & 676 & 205 \\
\hline 1999 & Federal & 72.604 & * & * & * & 18.041 & 2.820 & 872 & 175 \\
\hline 2000 & Federal & 69.411 & 11.774 & 9.682 & 25.079 & 18.251 & 3.359 & 1.057 & 209 \\
\hline 2001 & Federal & 60.628 & 10.633 & 8.317 & 21.319 & 16.401 & 2.742 & 972 & 244 \\
\hline 2002 & Federal & 61.341 & 10.377 & 7.694 & 21.866 & 17.133 & 2.905 & 1.080 & 286 \\
\hline 2003 & Federal & 62.928 & 9.933 & 7.778 & 22.950 & 18.470 & 2.631 & 914 & 252 \\
\hline 2004 & Federal & 63.035 & 9.299 & 6.923 & 23.693 & 18.844 & 2.960 & 1.019 & 297 \\
\hline 2005 & Federal & 63.779 & 8.770 & 6.786 & 24.640 & 18.045 & 3.861 & 1.289 & 388 \\
\hline 2006 & Federal & 65.581 & 8.090 & 7.064 & 25.561 & 18.709 & 4.254 & 1.463 & 440 \\
\hline 2007 & Federal & 69.301 & 7.810 & 6.633 & 26.942 & 20.768 & 5.028 & 1.550 & 570 \\
\hline 2008 & Federal & 69.625 & 6.033 & 7.673 & 27.020 & 19.783 & 6.552 & 1.889 & 675 \\
\hline 2009 & Federal & 96.786 & 7.284 & 6.100 & 33.474 & 30.582 & 14.845 & 3.406 & 1.095 \\
\hline 2010 & Federal & 100.683 & 6.052 & 5.968 & 34.036 & 27.479 & 20.938 & 5.208 & 1.002 \\
\hline
\end{tabular}

* Sem graduação 50.696

Fonte: Elaboração própria segundo dados (BRASIL, 1995-2010). Grifo nosso.

O crescimento das instituições públicas no período de 1995 a 2010 foi de 32,38\%, o crescimento das matrículas foi de $126,90 \%$, no entanto, podemos verificar certa discrepância no crescimento de docentes e técnicos administrativos, enquanto a função de docente teve um aumento de 76,70\%, o aumento de técnicos administrativos foi de $0,16 \%$, ou seja, praticamente não mudou a quantidade de técnicos administrativos, o que houve foi por um bom período o decréscimo acentuado, e nos últimos dois anos a retomada de contratações. Com a diminuição da quantidade de técnicos administrativos, que são os funcionários que dão suporte ao professor, e também a questão de serviços burocráticos e técnicos, cabe então ao professor realizar algumas dessas funções e também ocorre a sobrecarga dos técnicos existentes.

Como uma das medidas do REUNI é ter uma proporção de 18 alunos por professor, também prejudica tanto o professor que não pode dar a atenção necessária para o aluno, e também precariza seu trabalho, visto que, têm cada vez mais provas, trabalhos e alunos para orientar.

Neste sentido, o trabalho do professor se torna cada vez mais precarizado, porque tem que fazer funções que não são do seu cumprimento obrigatório, não tendo tempo para preparar melhores aulas, ou orientar pesquisa e extensão.

\section{CONSIDERAÇÕES FINAIS}

Os dados apresentados, em primeiro plano pelo governo federal, acerca da expansão e interiorização do ensino superior federal, apresentam com um primeiro olhar 
uma melhoria significativa para os padrões da educação superior no Brasil, principalmente em termos quantitativos. No entanto, os profissionais mais afetados desse processo, professores e técnicos administrativos, não estão percebendo expansão no mesmo ritmo e com a qualidade que se espera de uma instituição pública, que sempre aparece nos discursos oficiais oferecendo "Educação pública, gratuita, laica e de qualidade".

Os projetos divulgados de expansão, interiorização e, provável, democratização do Ensino Superior requerem outros investimentos, além da infraestrutura básica, de pessoal qualificado e dos equipamentos utilizados. Torna-se necessária, de início, uma ampliada discussão sobre os objetivos e possibilidades dessa nova instituição que surge para atender aos anseios das populações ainda marginalizadas pela incapacidade de lograr sucesso intelectual proporcionado pelo convívio acadêmico e científico, trabalho que se oferece em instituições públicas de ensino superior com infraestrutura e de pessoal que apresente condições materiais concretas para a plena realização deste trabalho.

\section{REFERÊNCIAS}

BRASIL, MINISTÉRIO DA EDUCAÇÃO. Reforma da Educação Superior: Reafirmando Princípios e Consolidando Diretrizes da Reforma da Educação Superior. Brasília, 2004a.

, MINISTÉRIO DA EDUCAÇÃO/INEP. Censo da educação superior: 2002 resumo técnico. Brasília, 2002a.

MINISTÉRIO DA EDUCAÇÃO/INEP. Censo da educação superior: 2010 resumo técnico. Brasília, 2010a. p.30.

Brasília, 1995.

, MINISTÉRIO DA EDUCAÇÃO/INEP. Sinopse estatística do ensino superior.

, MINISTÉRIO DA EDUCAÇÃO/INEP. Sinopse estatística do ensino superior. Brasília, 1996.

, MINISTÉRIO DA EDUCAÇÃO/INEP. Sinopse estatística do ensino superior. Brasília, 1997.

, MINISTÉRIO DA EDUCAÇÃO/INEP. Sinopse estatística do ensino superior. Brasília, 1998.

, MINISTÉRIO DA EDUCAÇÃO/INEP. Sinopse estatística do ensino superior. Brasília, 1999.

, MINISTÉRIO DA EDUCAÇÃO/INEP. Sinopse estatística do ensino superior. Brasília, 2000.

, MINISTÉRIO DA EDUCAÇÃO/INEP. Sinopse estatística do ensino superior. Brasília, 2001.

, MINISTÉRIO DA EDUCAÇÃO/INEP. Sinopse estatística do ensino superior. Brasília, 2002b.

, MINISTÉRIO DA EDUCAÇÃO/INEP. Sinopse estatística do ensino superior. Brasília, 2003.

, MINISTÉRIO DA EDUCAÇÃO/INEP. Sinopse estatística do ensino superior. Brasília, 2004b.

, MINISTÉRIO DA EDUCAÇÃO/INEP. Sinopse estatística do ensino superior. 
Brasília, 2005. Brasília, 2006.

, MINISTÉRIO DA EDUCAÇÃO/INEP. Sinopse estatística do ensino superior. Brasília, 2007b.

MINISTÉRIO DA EDUCAÇÃO/INEP. Sinopse estatística do ensino superior. Brasília, 2008.

, MINISTÉRIO DA EDUCAÇÃO/INEP. Sinopse estatística do ensino superior. Brasília, 2009.

, MINISTÉRIO DA EDUCAÇÃO/INEP. Sinopse estatística do ensino superior. Brasília, 2010b.

MINISTÉRIO DA EDUCAÇÃO/INEP. Sinopse estatística do ensino superior. PRESIDÊNCIA DA REPÚBLICA. Decreto $n^{\circ}$ 6096, Brasília, 2007a. , PRESIDÊNCIA DA REPÚBLICA. Decreto-Lei $n^{\circ}$ 9394, Brasília, 1996.

DIAS SOBRINHO, J. Dilemas da Educação Superior no Mundo Globalizado. Sociedade do Conhecimento ou Economia do Conhecimento? Casa do Psicólogo, São Paulo, 2005. p.168.

HARVEY, D. Condição pós-moderna: uma pesquisa sobre as origens da mudança cultural. Tradução: Adail Ubirajara e Maria Stela Gonçalves. 5a. Ed. - S. Paulo: Edições Loyola, 1992.

LIMA, K. R. S. Universidades Federais e o REUNI: alterações nas funções da universidade pública brasileira. Revista Advir, Rio de Janeiro, 2009, n²3, p 20-27.

MANCEBO, D.; OLIVEIRA, J. F.; MOROSINI, M. C.. Algumas estatísticas relevantes para a análise do trabalho docente. Associação Nacional de Pós-graduação e Pesquisa em Educação - ANPED, 2012.

PEREIRA, L. C. B. Reforma Gerencial de 1995. Disponível em <http://www.bresserpereira.org.br/rgp.asp>. Acesso em 12/09/2011)

SANTOS, B. S.; A Universidade no Século XXI: Para uma reforma democrática e emancipatória da Universidade. São Paulo: Editora Cortez, 2004. p.42-89.

TEIXEIRA, A. Educação e universidade. Rio de Janeiro: UFRJ, 1998.

\footnotetext{
${ }^{1}$ PPGE/UFSCar

2 PPGE/UFSCar

Recebido: agosto-13 Aprovado: setembro-14
} 